\title{
Phenomenological Reflections on the Structure of Transformation: The Example of Sustainable Agriculture
}

\author{
ELIZABETH A. BEHNKE \\ Study Project in Phenomenology of the Body, PO Box 66, Ferndale WA 98248, USA \\ Email:sppb@openaccess.org
}

\begin{abstract}
"But above all, we are the seeds: and we make ready to throw ourselves out of ourselves and into something else, something much higher, something that carries the name of spring...

To be inside the phenomena, always inside them: to be seed and always to lean upon your own earth." - from Nichita Stănescu, "A unsprezecea elegie" (Stănescu 1977: 97).

After outlining how putting phenomenological methods into practice can help to foster an attitude conducive to cultural transformation, I consider both mainstream and alternative ways in which the sense, "food", is constituted and present some parallels between the constitution of the "physicalistic thing" and the constitution of the "commodity", concluding with some remarks on the importance of a phenomenological retrieval of situated lived experience.
\end{abstract}

Keywords: phenomenology, Husserl, food, commodity, transformation

The purpose of this paper is twofold. First, I want to suggest that the very practice of phenomenology itself includes transformative elements, prefiguring a possible kinship between phenomenologists and environmental advocates or other proponents of cultural change. But I also want to take some preliminary steps toward a phenomenological analysis of a topic in which issues of both the "natural" and the "cultural" environment are woven into a single (and sometimes fragile) fabric: namely, the food we eat. This in turn will entail some investigation into certain parallels between the constitution of the "physicalistic thing" in the objective natural-scientific attitude and the constitution of the "commodity" in the commercial corporate attitude. For the most part, I will be following Husserl, but I will be making use of Husserlian methods and research results in order to carry out new analyses of (and from within) the phenomena themselves, rather than commenting upon Husserl's philosophy'. In this way I hope to present phenomenology as a living tradition with much to contribute to our current crises and challenges - and to the cultural transformations they call for.

1 References to Husserl 1950ff. will be cited by volume number/page or section ( $\$$ ) number; references to Husserl 2001ff. will take the same form, preceded by the abbreviation HM. For Husserl's own approach to the issue of cultural renewal, see the essays written in the 1920s for the Japanese journal Kaizo (27/3-94). 


\section{TRANSFORMATIVE MOMENTS WITHIN PHENOMENOLOGICAL PRACTICE}

On the one hand, it is certainly possible to see phenomenology as a merely theoretical endeavor. On the other hand, however, H. Spiegelberg (1975: 54-71) has suggested that phenomenology can indeed be of practical value, discussing a number of its "existential uses". I would like to pursue this further by indicating how carrying out an original phenomenological investigation involves making use of a number of interrelated skills and attitudes that can be of help in transformative practice in other fields ${ }^{2}$.

To begin with, the natural attitude is quite precisely not aware of itself $a$ s "the natural attitude", but is first revealed as such within a phenomenological attitude that can make it a theme for description, characterizing it, for instance, in terms of a life lived in automatic acceptance of a ready-made world in which "this is the way it is". Even bringing the status quo to explicit awareness is already a practical step toward the possibility of changing it. When we fully engage the phenomenological epochē and reduction, however, we inaugurate several further shifts. First of all, we suspend the naive and all-pervasive ontic acceptance signaled by the "is" in "this is the way it is". At the same time, we open up an experiential dimension within which we can inquire into the "how of the givenness" of things, transforming fixed "realities" into lived meanings. This can also be a liberating move - think of asking yourself the question "What am I actually experiencing?" rather than automatically assuming in advance that everything is the way "they say" it is. In other words, the turn to experiential evidence can foster a kind of grassroots movement of experiencers who are not going to be argued out of their experience by "experts" or other authorities.

In addition, the disclosure of the universal a priori of correlation $(6 / \$ 46)$ between "experiencing" and "that which is experienced" invites a detailed investigation of the patterns of interests, attitudes, and values that are implicated in the constitution of a situation as being "this way". Here a phenomenological critique of presuppositions can bring to light not only the "general assumption" governing each sphere of experience (HM1/184f.), but also the specific "hidden" apperceptive traditions (34/363; cf. Behnke 2011) that tacitly frame our experience in advance, so that we always already perceive something as "this type of thing". In this way the phenomenological analysis can awaken us to the fact that our current experiential situations have their own historical depth - we may be functionally participating in social or cultural structures we were not previously aware of, shaped by sedimented styles of thinking, speaking, perceiving, and acting whose dynamics can be consciously reactivated, criticized, and shifted (cf. 6/72f.). Thus phenomenology can undermine the unquestioned assumption that "this" is the way it is, transforming premises taken for granted into phenomena whose origins and structures can be described (cf. 24/214, 370) - and whose limits can then be articulated.

There is also a transformative moment implicated in the very attitude of an eidetic phenomenology focused on the recurring structures of experience that allow us to recognize "the same kind of thing" even though the actual facts vary on each occasion. Here the key is an "exemplicating" move that takes something as "an" example-of an experiential pattern or structure. But to recast a given example in this way already "possibilizes" it: it becomes one possibility among others, a possibility that may happen to be actual, but could be otherwise

2 Of course, phenomenologists have no monopoly on the skills and attitudes in question. But I do want to suggest that the Husserlian phenomenology that is my concern here is a tradition of method shaped by the possibility in principle of cultivating these skills and attitudes in order to employ them in concrete investigations of particular themes and topics. 
(see Zaner 2012: Ch. 2-4). And this can take place in more than one way. On the one hand, the same experiential structure can be instantiated by more than one set of facts; for example, if we have decided to solve a particular problem in a certain way, we may suddenly see that we can achieve the same outcome using entirely different procedures. On the other hand, the current "givens" may turn out to be an example of a completely different lived meaning than the one we initially experienced; think, for instance, of the shift from seeing something as "garbage" to seeing it as material for recycling or composting. In this way a phenomenological perspective can help to free us from what V. Shiva has called "monocultures of the mind", thereby allowing the emergence of a "context of diversity" in which alternatives are not excluded in advance (Shiva 1993: 5).

Later in this paper I will try to put all this into practice by addressing a concrete case at the intersection of the "natural" and the "cultural" environment. But first I will turn to some of Husserl's own phenomenological analyses for some distinctions that can serve as useful resources in times of challenge and change.

\section{TOWARD A BRIEF PHENOMENOLOGY OF "NORMALITY" AND "ANOMALY"}

Husserl offers many analyses of normality, often involving the contrast between "normal" and "abnormal" perception. Here, however, I will focus on the connection he establishes between normality and concordance. Normal experience unfolds along the lines of a coherent network of horizonal predelineations within which we find a continual interplay of anticipation, on the one hand, and confirmation or correction, on the other. If the course of harmonious experience is momentarily disrupted when a specific expectation is disappointed, the break is usually repaired in such a way that normal coherence is reinstated and maintained at higher levels, all the way up to the world itself as the horizon of horizons that accommodates both our own familiar home-world and the other cultural worlds we may encounter. Even major disruptions of everyday normality such as floods and earthquakes still belong to the "normal style" of the world as a whole, and are met with "normal" ways of reacting to them $(39 / 198)$.

Yet what happens when something stubbornly refuses to "fit" into the intricate nexus of experiential possibilities that not only mutually refer to one another, but mutually support one another? Here we can speak not simply of "abnormality", but more precisely of "anomaly". And when something anomalous irrupts at the level of cultural change, there are typically two sorts of responses. First of all, much social energy may be directed toward attempting to contain or control the anomaly. For example, pejorative language may be developed in order to denigrate social movements. Think, for instance, of the practice of referring to environmentalists as "tree-huggers", even if most environmental advocates have never actually hugged a tree personally (or with a circle of friends, as with the huge trunk of a tree that is no longer standing in Kaunas, one that is far too big for a single pair of arms to embrace). And there are, of course, many other strategies for attempting to co-opt change in progress. Yet there is a second sort of response as well, one that sees the anomaly as bearing the seeds of a new normality (cf. HM8/434n.1) - a new network of implications that predelineate other possibilities rather than perpetuating the presuppositions of the status quo. I will now attempt to flesh out these theoretical considerations by addressing current patterns of food production and distribution in terms of the contrast between the current "normality" of global agribusiness and the "anomaly" - or the emerging (and ancient) alternative normality - of small-scale, local, sustainable organic farming. This is obviously 
a huge topic. But I can at least offer a brief example of how we might approach these matters phenomenologically.

\section{FOOD FOR AND FROM A LIVING PLANET}

I will begin by inquiring into the sense, "food", as constituted in mainstream experience in North America. The lived meaning of food can be extremely complex. For example, many people may experience certain foods as part of their cultural identity, and in some traditions, the categories of "food" and "medicine" may overlap. But in general, food today is typically experienced as a ready-made item in a ready-made world. Here the term "ready-made" does not merely refer to something that has already been processed or prepared. Instead, it highlights the anonymous character of food, which is simply "there", available for purchase yearround, automatically accepted as a part of the cultural environment (cf. Wirth 2017: 236ff.). If the word "natural" occurs on a food label at all, it may simply refer to the absence of certain additives, not to the natural environment per se.

This complex situation - which I have barely sketched here - stands in contrast to the way the sense, "food", is constituted in the emerging alternative normality of sustainable, organic farming in harmony with the natural ecosystem. Phenomenological reflection suggests that in this approach, food is an "achievement", as indicated in Wendell Berry's famous notion that food is an agricultural act. And the emerging view is concerned to retrieve this act from its anonymity - for example, by exposing the practices of the agro-industrial complex, with its giant transnational conglomerates and cartels, its fuel-intensive long-distance shipping, its emphasis on standardization, and its reliance on chemical fertilizers, pesticides, and herbicides. At the same time, the emerging movement toward sustainability is concerned to empower those growing food in organic, human-scale farms and gardens and marketing it locally ${ }^{3}$. This leads the phenomenologist to ask: what does it take for an emerging "anomaly" to become a functioning "normality" in its own right? Given the theoretical framework that I have already outlined, the answer has to do with developing a rich, concordant network of mutually implying, mutually supporting possibilities, including, for instance, the availability of open-pollinated seed, whose plants make seeds that can be saved each year for the next year; the preservation of biodiversity, and especially of crops uniquely suited for local and regional conditions; access to appropriate tools, training, and information; connections with living traditions of local/indigenous knowledge; and a community, including those who value eating local, organic food as well as those engaged in growing $\mathrm{it}^{4}$. Of course, more is required as well, such as access to fertile, uncontaminated soil and to unpolluted fresh water, along with a robust population of pollinating insects - dimensions of the natural environment that have already been significantly altered by human activity. But the cultural environment proper to sustainable agriculture - the shared nexus of intersubjective meanings informing and supporting its practice - is itself characterized by a deep commitment to the health of the natural environment, so that what is "cultivated" and nurtured is truly the broadest possible horizon: the health and well-being of the whole.

3 See, e. g., Halweil 2004, which not only documents mainstream agricultural practices and their attendant problems, but offers concrete instances of successful alternative practices worldwide.

4 The practical source I have found most helpful in actualizing the alternative paradigm is Jeavons 2012. Other works I have turned to include, for example, Ashworth 2002; Bonsall 2015; Cech 2009, 2016; Coleman 1999; Deppe 2000, 2010, 2015; Katz 2003, 2012; Logsdon 2009; Phillips 2011; and Stamets 2005. Bates 2010, Heekin 2014, and Prechtel 2012 provide further specific examples, cultural contexts, and inspiration. 
All of this is very different from the referential nexus comprising the usually anonymous horizon of the mainstream model - huge factory farms (many relying on government subsidies); monoculture rather than biodiversity, with an emphasis on uniform produce that can be transported in standardized containers; mass marketing promoting a homogenization of culture and helping to drive consumer food prices ever higher; and a world where childhood obesity is a problem in some regions while children are starving to death in others. Phenomenological reflection might then lead to the question: how is the sense, "food", constituted from the point of view of the agribusiness conglomerates? Of course, this question also has its horizon of further questions. For example, one might contrast the agribusiness sense with a further set of alternative senses, such as food as a human right; food as a generative heritage; food as a source of social change; food as gathering a world in Heidegger's sense; food as the nourishment we do not "represent", but "live from" in Levinas's sense; food as the true communion between our flesh and the flesh of the world in Merleau-Ponty's sense; or food as a fundamental moment in the web of life, which is not an object to be observed from the outside, but a primal matrix to be lived from within. Here, however, I will set aside the latter list of possibilities in order to suggest that in the mainstream model, food is most essentially a commodity. I shall accordingly turn to the question of the constitution of the "commodity" per se, using Husserl's analyses of the constitution of "objectivity" in the natural sciences as a springboard for some phenomenological analysis of the commercial corporate attitude in which so many of our current crises seem to be rooted.

\section{FROM THE CRISIS OF EUROPEAN SCIENCES TO THE CRISIS OF CORPORATE CULTURE}

Husserl's discussions in the Crisis ${ }^{5}$ of the generative-historical constitution of natural-scientific objectivity can be understood as resting upon and refining the static-phenomenological account offered in Ideas II of the constitution of the physicalistic thing. There he begins $(4 / \$ 11)$ by specifying that nature as a sphere of mere things is reached by an abstraction that sets aside all predicates pertaining to value or practice; then $(4 / \$ 13)$ he highlights a certain homogenization such that these material things are universally to be understood in terms of their extension. He further emphasizes not only the possible fragmentation of extended things into smaller extended pieces (4/30), but the divisibility of things into thing-systems composed of molecules or atoms (4/50ff.), preparing the way for what we may term the unitization of substantial reality, whether in terms of the units of measurements used to determine the magnitudes of extensions or the ultimate homogeneous units of matter as understood

5 Recent studies of Husserl's The Crisis of European Sciences and Transcendental Phenomenology have raised a number of issues that are philosophically relevant to my descriptions and analyses. For example, Aldea (2016) explores the tension between eidetic-phenomenological investigations in search of invariant structures (including structures governing historical dynamics) and transcendental-historical reflections upon the historically situated origins of sedimented acceptances and patterns of meaning-constitution determining epistemic styles that shape entire regions of inquiry over time, while Ferencz-Flatz (2017) considers related issues in terms of the relation(s) between static and genetic phenomenology; Trizio (2016) and Heffernan (2017) discuss the sense of Husserl's notion of "crisis" with regard to the theoretical insufficiency of the very scientificity of the positive sciences and the severing of such sciences from the questions of meaning and value; and Knies (2016) critically examines Husserl's emphasis in the Crisis on "Europe" and "Europeanization". However, my aim here is not to respond to the points made in the secondary literature, but to use Husserl's methods in order to investigate concrete themes that Husserl himself did not address. 
in classical physics ${ }^{6}$. But a further move is necessary as well $(4 / \$ 18)$, one in which Husserl goes on to demonstrate how the constitution of the physicalistic thing requires overcoming various relativities - notably, those due to each situated observer being presented with a different appearance of the thing, and moreover, those due to variations in these observers' sensory capabilities. The end result, then, is that the abstraction from value-predicates and practical predicates is accompanied by an abstraction from any subject-dependent relativity whatsoever; thus both the experiencing subject and the experiential world are banished from the realm of objective science, leaving only the "physicalistic thing, determined logico-mathematically" (4/82). And eventually, we may see all this as undergoing a universalization reaching the "ultimate objectivity" of "the 'true' world" (4/89).

Husserl returns to this trajectory in texts from various periods (see, e.g., 39/265ff., from 1926). But it reaches its culmination in the Crisis, where he characterizes the Galilean search for objectivity as a search for a method that can "overcome the relativity of subjective interpretations [Aufassungen]" - a relativity that "is, after all, essential" to the world as concretely experienced - in order to reach "an identical, nonrelative truth" verifiable for anyone able to "understand and use this method" (6/27). Here the procedure leading to a "physicalistic naturalism" (6/68) also requires an abstraction yielding ideal geometrical shapes; an accompanying homogenization that excludes the diverse textures of a concretely lived space in favor of a uniform, mathematized space; a thoroughgoing unitization that is not confined to the practical application of units of spatial measurement, but accomplishes a further algebraization of geometrical space via Cartesian coordinates, allowing any point of any given geometrical figure to be specified by a pair of numbers (cf. 6/38, 44, 387); and a universalization such that these procedures (and the attitude in which they are carried out) are applied to everything, including living beings (6/67f.; cf., e.g., 41/296) ${ }^{7}$. But the flight from the relativity of subjective experience is problematic for Husserl, despite its technological successes. As is well known, he points out, for example, that the resulting objectivistic attitude leads to taking for "true being" what is actually a method (6/52); thus even though we may accept the validity of these methods within the spheres proper to them, their claim of "absolute truth" (6/92) must be subjected to critique. In addition, the hegemony of an objectivistic attitude completely obscures the lifeworldly foundation of the sciences themselves (6/48ff.), a foundation whose dignity must be restored so that the "despised doxa" (6/158) is no longer disparaged, but acknowledged as the original source of the generative-historical achievements associated with the turn to theoria and epistēme in the Greeks, and thus with the Western tradition per se. Yet it is not enough merely to recognize the pregiven surrounding world as the ground upon which the theoretical-logical praxis of science rests $(6 / \$ \$ 33 \mathrm{f}$.), for as Husserl's extensive research manuscripts on the lifeworld

${ }^{6}$ Husserl (32/89f., 94f.) considers the latter point in more detail in his 1927 discussions of Heinrich Rickert's characterization of the "ultimate things" of nature (i.e., of the world considered as value-free) as qualitatively all of one species and quantitatively indivisible, i.e., we may add, constituted according to the principles of abstraction, homogenization, and unitization - all of which Husserl sometimes sums up as "idealization". Note, however, that in the course of contrasting "physicalistic" reality and "morphological" reality in a research manuscript from 1926 (41/278-296), he himself denies that the geometrizing/mathematizing idealization could ever actually reach such ultimate, absolutely indivisible realities, and he insists in addition on the need to maintain a distinction between "exact, idealizing sciences" and investigations of the "concrete morphological structure of the world" (41/284f.).

This drive toward progressive abstraction and control through numerical coding and calculation has, of course, continued in the digital age, where everything is translated into "information" to be retrieved and manipulated electronically at will. 
make clear, the relativity of situational truth is an essential moment of the surrounding world of direct experience. The structures of lifeworldly situativity must accordingly be described in their own right (see 39/145-205), which may involve realizing that even cultures we term "primitive" have their own modes of knowledge, leading, for example, to the question of the legitimacy of explications that have all been framed in terms of the "European" (39/170; cf. 6/14).

Such a train of thought is reminiscent of V. Shiva's approach to "monocultures of the mind", where she not only specifies many facets of the "crises of the dominant knowledge system" (Shiva 1993: 59f.), but identifies this dominant knowledge system itself as a local ("Western") system that has emerged within a particular local culture, yet has awarded itself the status of "a universal tradition, inherently superior to local systems" (Shiva 1993: 10; cf. 71, 135). This, however, is merely a spurious "universality", since it is spread by practices of colonization and globalization that denigrate other local traditions, diminishing alternative systems of knowledge to the point that they are made to disappear, just as dominant political systems may make dissidents disappear (Shiva 1993: 9ff.). Furthermore, "Over and above rendering local knowledge invisible by declaring it non-existent or illegitimate, the dominant system also makes alternatives disappear by erasing and destroying the reality which they attempt to represent", fragmenting what local knowledge sees as integrated and effacing "the very conditions for alternatives to exist, very much like the introduction of monocultures [of introduced plant varieties] destroying the very conditions for diverse species to exist" (Shiva 1993: 12; cf. 50ff.).

What is interesting here is that Shiva does not simply equate the dominant knowledge system with the objective natural sciences; indeed, in demonstrating the damage done by this globalized "Western" knowledge system, she herself makes ample use of natural-scientific methods and results ${ }^{8}$. In what follows, I shall not review her excellent documentation of the crises in agriculture that can be traced to the dominant knowledge system. Instead, I shall attempt to complement her work, taking the Husserlian analyses already sketched above in a new direction with some preliminary phenomenological reflection on globalized corporate culture.

In some of his descriptions of lifeworldly situativity (see, e.g., 39/190-204), Husserl grapples with the problem of the relation between particular situations and surrounding worlds, on the one hand, and the total situation, on the other, - "the" world within which particular cultural lifeworlds and traditions have their place even before the abstractions of objective science come into play. Here particular peoples come to understand their foreign counterparts as fellow members of a single, universal humankind, encountering the same things "we" do, but experiencing them differently and having a different "worldview" ("Weltbild"). After describing these matters, Husserl goes on to say - writing in 1932 - that this universal humankind has nevertheless not yet led to a single fixed tradition or worldview shared by humanity as a whole (39/203). In our times, however, a globalized corporate worldview has certainly become a candidate vying for this role, not only affecting business practices per se, but "flowing back into" $(6 / 115,141$. 1$)$ everyday experience in the lifeworld. And here we rejoin our question regarding the constitution of something as a commodity ${ }^{9}$.

As Husserl points out in his brief description of the lived experience of coal (4/187f.; cf. Skocz 2007: 575-577), humans have needs, and there are goods that have value for us in fulfilling these needs; thus coal is valuable to me because I can use it to heat a room and feel warm.

8 Similarly, it is the scientists who point to the devastating effects of climate change, while politicians in many countries continue to insist on protecting corporate interests.

9 See also Seebohm 2015: Ch. 10.5, especially 333ff., on the development of market economies, currencies, commodities, and attitudes oriented toward maximizing profits. 
But in addition to this immediate experience of coal as keeping me warm, there is a further stratum - based on the original lifeworldly sense - in which coal is seen as a commodity, i.e., as something available for sale (4/188). We could carry Husserl's description further by pointing out that when coal is seen as a commodity, the person experiencing it is no longer just someone needing and appreciating warmth, but has become, in this new stratum of sense, a consumer. Once something has been constituted as a commodity, however, it loses its direct ties to the experiential realm of concrete human needs, and can be seen as something to be bought, sold, hoarded, etc., for its own sake simply because it has actual or potential "commercial" value. Similarly, the consumer is no longer a concretely situated person, but is defined solely in terms of having money to spend. Hence the twin categories of "consumer" and "commodity" rely upon the move of abstraction already mentioned. The move of homogenization then takes several forms. If we trace the constituted formation, "consumer/commodity", back to the habitual attitude of a (collective) constituting consciousness, we find what may be termed the commercial corporate attitude, for which the abstraction to the commodity is infinitely extended in both an inclusive and an exclusive way: on the one hand, anything whatsoever can potentially be seen as a commodity; on the other hand, what has no immediate commercial value for the business or industry concerned is ignored or eradicated. Thus, for example, the dominant attitude sees forests only in terms of the marketable timber produced once the trees have been cut down, whereas local knowledge systems see forests as living, renewable sources of foods, medicines, animal fodder, soil fertility, and water conservation, as well as of wood (Shiva 1993: 12-39; cf. 72, 85ff.). Moreover, all transactions within the homogeneous realm of the commodity (including not only buying and selling, but also more complex commercial activities) are equally constituted as occasions for profit and loss, all calculated in identical terms requiring a particular type of unitization: namely, in units of money (cf. 39/521f.), which are subjected to the mathematical laws peculiar to corporate accounting practices. Finally, the attitude that sees everything solely in terms of its profitability is ultimately universalized. Money itself becomes a commodity, as currencies are traded, interest is paid on loans, etc., while even potential profits that fail to be realized are assigned monetary value, as when circumstances (e.g., traffic jams, power outages, employee stress or other health issues) are said to result in millions of dollars (or other currency) of "lost productivity". And if something cannot be grasped in terms of its profitability, it becomes invisible and ceases to count at all.

Now many have noted that what corporations do may damage ecosystems without the corporations ever paying for the damage; others have noted that corporations fail to value what they do not have to pay for, even while relying on free access to clean air and water, etc., to run their business. Some environmental advocates have therefore suggested using the notion of "natural capital" (an idea initially introduced by Amory Lovins) to bring the ecological presuppositions of commercial enterprises back into the equation, restoring to visibility what becomes invisible when immediate profitability vis-à-vis money actually spent is the only criterion (cf., e.g., Shiva 1993: 58). Charging polluters for the damage they cause is undoubtedly a sound idea. However, the further commodification, privatization, and centralized control of the ecological presuppositions shared by all may simply worsen our current crises. Moreover, such measures fail to address much of the collateral damage caused by the universalization of the commercial corporate attitude, including, for example, the extinction of cultural diversity and local knowledge systems, the loss of biodiversity, the erosion of sustainable livelihoods and human dignity, and so on (Shiva 1993: 65, 146f.). The true problem, in other words, lies in the ongoing threat to values that are irreducible in principle to commercial values, and that are inherently subject-relative. 


\section{CONCLUSIONS}

We may accordingly bring our provisional investigations to a close by summarizing two main approaches through which phenomenology can recognize and honor values beyond those of the commercial corporate attitude: namely, mundane phenomenology (lifeworldly phenomenology, phenomenological psychology) and transcendental phenomenology. The former is typically reached by placing scientific knowledge in brackets and returning to the world of prescientific experience, a move for which Husserl often uses the term Rückgang (going back); the latter, for which Husserl often uses the term Rückfrage (asking back), takes the phenomena - and their horizons - as clues (Leitfaden) from which to inquire back into the correlative attitudes, assumptions, interests, achievements, and essential styles of constituting (inter)subjective life ${ }^{10}$. Following the latter path would accordingly require, for instance, more detailed analyses of the ways in which the world is constituted for such dominant knowledge systems as the corporate mentality through such categories as consumers, commodities, and profits. Here the accent is on tracing "the way things are" back to the previously anonymous constitutive sources (cf. 6/\$29; 39/119), including the sedimented constitutive styles of generative-historical intersubjectivity, that hold this world in play, thereby opening up received frameworks of meaning for critique rather than simply taking them for granted. On the other hand, we must also continue to (re)establish the legitimacy of situated lifeworldly experience and its values; here the accent lies on further description of patterns of lived meanings, just as they are experienced in the natural attitude, within the subject-relative contexts we study ${ }^{11}$. Such work is particularly crucial in order to save endangered local knowledge systems, and thereby to foster a biodemocracy in which both biodiversity and the diverse communities that ultimately sustain it can be restored to health and wholeness (Shiva 1993: 88ff.; cf. 60-62, 159).

These, then, are at least two of the main ways in which phenomenology offers us the possibility of a new scientificity $(6 / 102,127,399)$ that can provide the intersubjective verifiability we require while preserving not only the subject-relatedness that makes our earth a surrounding world or "environment" (Umwelt) in the first place, but also the situated world-relatedness that makes us human. It is true that phenomenological investigation might not, in and of itself, feed a starving person, or renew depleted soil, or restore the pollinators killed by pesticides, or heal the air and the water of a wounded planet, or halt the globalization of the corporate mentality. Like a seed, however, the retrieval and rehabilitation of the experiential dimension is capable of unfurling into something beyond itself, implying a world in which it can truly flourish. Thus for me, the task of phenomenology in a time of political crisis, cultural change, and environmental challenges is not only to clarify our predicaments, but also to contribute - in whatever way possible - to transforming our traditions in ever more fruitful ways ${ }^{12}$.

Received 28 August 2017

Accepted 23 November 2017

${ }^{10}$ On Rückgang and Rückfrage, see Husserl 1999: 49 (cf. 34/582f.); on the latter possibility in particular, see, e.g., 6/100f., 154, 161f., and cf., e.g., 34/205; 17/252.

${ }^{11}$ Cf., e.g., the excellent discussions in Seamon 1979. Note that "patterns" of lived meanings may be discerned at various levels, so that although the findings will refer to shared experiential possibilities rather than to any particular set of facts, it is not always appropriate to work solely at the level of the most universal structures: the point is not merely to assert the validity of the correlational a priori as a general principle of subject-relatedness, but to explicate it in detail in specific contexts and types of situations.

12 I would like to thank the anonymous reviewers for suggesting some ways to improve this article. 


\section{References}

1. Aldea, A. S. 2016. "Phenomenology as Critique: Teleological-Historical Reflection and Husserl's Transcendental Eidetics", Husserl Studies 32(1): 21-46.

2. Ashworth, S. 2002. Seed to Seed: Seed Saving and Growing Techniques for Vegetable Gardeners. 2nd edn. Decorah, Iowa: Seed Savers Exchange.

3. Bates, A. 2010. The Biochar Solution: Carbon Farming and Climate Change. Gabriola Island, British Columbia: New Society.

4. Behnke, E. A. 2011. "Critique of Presuppositions, Apperceptive Traditionality, and the Body as a Medium for Movement”, Studia Phaenomenologica 11: 77-98.

5. Bonsall, W. 2015. Will Bonsall's Essential Guide to Radical, Self-reliant Gardening: Innovative Technologies for Growing Vegetables, Grains, and Perennial Food Crops with Minimal Fossil Fuel and Animal Imports. White River Junction, Vermont: Chelsea Green.

6. Cech, R. 2009. The Medicinal Herb Grower: A Guide for Cultivating Plants That Heal. Williams, Oregon: Horizon Herbs.

7. Cech, R. 2016. Making Plant Medicine. 4th edn. Williams, Oregon: Herbal Reads.

8. Coleman, E. 1999. Four-season Harvest: Organic Vegetables from Your Home Garden All Year Long. 2nd edn. White River Junction, Vermont: Chelsea Green.

9. Deppe, C. 2000. Breed Your Own Vegetable Varieties: The Gardener's and Farmer's Guide to Plant Breeding and Seed Saving. 2nd edn. White River Junction, Vermont: Chelsea Green.

10. Deppe, C. 2010. The Resilient Gardener: Food Production and Self-reliance in Uncertain Times. White River Junction, Vermont: Chelsea Green.

11. Deppe, C. 2015. The Tao of Vegetable Gardening: Cultivating Tomatoes, Greens, Peas, Beans, Squash, Joy, and Serenity. White River Junction, Vermont: Chelsea Green.

12. Ferencz-Flatz, C. 2017. "Zur geschichtlichen Wende der genetischen Phänomenologie. Eine Interpretation der Beilage III der Krisis", Husserl Studies 33(2): 99-126.

13. Halweil, B. 2004. Eat Here: Reclaiming Homegrown Pleasures in a Global Supermarket. New York: W. W. Norton/Worldwatch Books.

14. Heekin, D. 2014. An Unlikely Vineyard: The Education of a Farmer and Her Quest for Terroir. White River Junction, Vermont: Chelsea Green.

15. Heffernan, G. 2017. "The Concept of Krisis in Husserl's The Crisis of the European Sciences and Transcendental Phenomenology", Husserl Studies 33(3): 229-257.

16. Husserl, E. 1950ff. Husserliana. Den Haag/Dordrecht: Martinus Nijhoff/Kluwer/Springer.

17. Husserl, E. 1999. Erfahrung und Urteil. Untersuchungen zur Genealogie der Logik, ed. L. Landgrebe. Hamburg: Felix Meiner.

18. Husserl, E. 2001ff. Husserliana Materialien. Dordrecht: Kluwer/Springer.

19. Jeavons, J. 2012. How to Grow More Vegetables Than You Ever Thought Possible on Less Land Than You Can Imagine. 8th edn. Berkeley: Ten Speed Press.

20. Katz, S. E. 2003. Wild Fermentation: The Flavor, Nutrition, and Craft of Live-culture Foods. White River Junction, Vermont: Chelsea Green.

21. Katz, S. E. 2012. The Art of Fermentation. White River Junction, Vermont: Chelsea Green.

22. Knies, K. 2016. "A Qualified Defense of Husserl's Crisis Concepts", Metodo 4(1): 27-47.

23. Logsdon, G. 2009. Small-scale Grain Raising. 2nd edn. White River Junction, Vermont: Chelsea Green.

24. Phillips, M. 2011. The Holistic Orchard: Tree Fruits and Berries the Biological Way. White River Junction, Vermont: Chelsea Green.

25. Prechtel, M. 2012. The Unlikely Peace at Cuchumaquic - The Parallel Lives of People as Plants: Keeping the Seeds Alive. Berkeley: North Atlantic.

26. Seamon, D. 1979. A Geography of the Lifeworld. London: Croom Helm.

27. Seebohm, T. M. 2015. History as a Science and the System of the Sciences: Phenomenological Investigations.

Dordrecht: Springer.

28. Shiva, V. 1993. Monocultures of the Mind: Perspectives on Biodiversity and Biotechnology. London: Zed Books.

29. Skocz, D. E. 2007. "Husserlian Variations on Nature, Environment, and Earth: Toward a 'Green' Phenomenology", in Phenomenology 2005. Vol. 5: Selected Essays from North America, Part 2, ed. L. Embree and T. Nenon. Bucharest: Zeta Books, 563-592. 
30. Spiegelberg, H. 1975. Doing Phenomenology: Essays on and in Phenomenology. The Hague: Martinus Nijhoff.

31. Stamets, P. 2005. Mycelium Running: How Mushrooms Can Help Save the World. Berkeley: Ten Speed Press. 32. Stănescu, N. 1977. "Eleventh Elegy", trans. A. Bantas and J. Newlove, in Modern Romanian Poetry, ed. N. Catanoy. Oakville, Ottawa: Mosaic Press/Valley Editions, 94-97.

33. Trizio, E. 2016. "What is the Crisis of Western Sciences?", Husserl Studies 32(3): 191-211.

34. Wirth, J. M. 2017. "When Washing Rice, Know that the Water is Your Own Life: An Essay on Dōgen in the Age of Fast Food", in Ontologies of Nature: Continental Perspectives and Environmental Reorientations, ed. G. Kuperus and M. Oele. Cham: Springer, 235-244.

35. Zaner, R. M. 2012. At Play in the Field of Possibles. Bucharest: Zeta Books.

\title{
Transformacijos struktūros fenomenologiniai svarstymai: tvaraus žemès ūkio atvejis
}

\begin{abstract}
Santrauka
Bendrais bruožais aiškinamasi, kaip fenomenologinių metodų praktinis pritaikymas gali padèti puoselèti nuostatas, vedančias prie kultūros transformacijos, svarstoma tiek apie vyraujančius, tiek alternatyvius „maisto“ prasmès konstitavimo būdus ir pateikiamos paralelès tarp „fizikalistinio daikto" ir "prekès“ konstitavimo, o išvadoje - pastabos apie situacinès gyvenamosios patirties fenomenologinio atkūrimo svarbą.
\end{abstract}

Raktažodžiai: fenomenologija, Husserlis, maistas, prekè, transformacija 